\title{
The kinetic of point defect transformation during the annealing process in electron-irradiated silicon
}

\author{
G.P. Gaidar, A.P. Dolgolenko, P.G. Litovchenko \\ Institute for Nuclear Research, NAS of Ukraine, \\ 47, prospect Nauky, 03680 Kyiv, Ukraine \\ E-mail: gaidar@kinr.kiev.ua
}

\begin{abstract}
The A-centers (VO) annealing and transformation of precursors to form stable $\mathrm{C}_{\mathrm{i}} \mathrm{O}_{\mathrm{i}}$ defects during these processes are described. It was found the necessity to take into account annihilation of vacancy type defects with the interstitial type mobile defects to describe the annealing of defects. It was shown that the energies of migration for vacancy (V) and interstitial carbon atoms $\mathrm{C}_{\mathrm{i}}$ that are defined by the degree of their localization in silicon lattice at the temperature close to $550 \mathrm{~K}$ are equal $E_{m}^{\mathrm{V}}=1.1 \mathrm{eV}$ and $E_{m}^{\mathrm{C}_{\mathrm{i}}}=1.16 \mathrm{eV}$, accordingly. The values for potential barriers and their positions on the migration path of interstitial carbon atoms to oxygen $\left(\mathrm{O}_{\mathrm{i}}\right)$ in the region for capture of $\mathrm{C}_{\mathrm{i}}$ atom by $\mathrm{O}_{\mathrm{i}}$ atom (with the radius $14.7 \AA$ ) are determined. It was brought evidences that vibration band of absorption at $865.9 \mathrm{~cm}^{-1}$ is attributed to $\mathrm{A}$-center modified by carbon, and the $967.4 \mathrm{~cm}^{-1}$ band is attributed to a metastable state of $\mathrm{C}_{\mathrm{i}} \mathrm{O}_{2 \mathrm{i}}$ defect associated with an oxygen dimer. The position of the A-center donor level in the forbidden band of silicon is determined as $E_{\mathrm{V}}+0.415 \mathrm{eV}$.
\end{abstract}

Keywords: silicon, point defects, electron irradiation, annealing.

Manuscript received 21.10.10; accepted for publication 16.03.11; published online 30.06.11.

\section{Introduction}

In spite of considerable number of works concerning the annealing of radiation defects in silicon, in our opinion, this process is described only partially. For example, many authors usually use only two annealing mechanisms: migration to sinks and dissociation of defects. Therefore, when these two dominant defects in silicon $\left(\mathrm{C}_{\mathrm{i}} \mathrm{O}_{\mathrm{i}}\right.$ and VO) are annealed in the same temperature range $300 \ldots 400{ }^{\circ} \mathrm{C}$ and their centers coincide at the annealing stages, it is difficult to clearly define: either vacancies generated in the course of A-centers dissociation are captured by $\mathrm{C}_{\mathrm{i}} \mathrm{O}_{\mathrm{i}}$, or $\mathrm{C}_{\mathrm{i}}$ atoms released from $\mathrm{C}_{\mathrm{i}} \mathrm{O}_{\mathrm{i}}$ interact with $\mathrm{VO}$ ( $\mathrm{A}$ - center). But in any case, the $\mathrm{C}_{\mathrm{s}} \mathrm{O}_{\mathrm{i}}$ defects are formed as a result of annealing [1].

Point defects (vacancies and interstitial atoms) as well as their complexes with impurity atoms in silicon are the most completely studied. The activation energy of migration is one of the most important characteristics of the defects. So, the authors [2] compared the migration energy of interstitial atoms $\left(\mathrm{I}_{\mathrm{Si}}\right)$ and Frenkel pairs $(\mathrm{I}-\mathrm{V})$ with the migration energy of vacancy $\left(\mathrm{V}^{++}\right.$, $\left.0.33 ; \mathrm{V}^{0}, 0.45 ; \mathrm{V}^{=}, 0.18 \mathrm{eV}\right)$ measured by Watkins [3]. Herewith, the hydrogen molecules $\left(\mathrm{H}_{2}\right)$ were used as sinks for vacancies and interstitials silicon atoms created by irradiation of 6-MeV electrons. It was shown that the migration energy $\left(E_{m}\right)$ of $\mathrm{I}$ and $\mathrm{I}-\mathrm{V}$ almost do not differ from the migration energy of vacancies in the respective charge states. Investigation of the annealing of defect clusters, the main defects in which the di- and tri-vacancy defects are, allowed to determine the activation energies of their annihilation with the interstitial and di-interstitial silicon atoms ( $E_{a}^{\mathrm{I}}=0.91 \mathrm{eV}$ and $E_{a}^{\mathrm{I}_{2}}=0.74 \mathrm{eV}$, respectively), as well as the migration energy of vacancies $\left(E_{\mathrm{V}}^{m}=0.8 \mathrm{eV}\right)$ at the temperature about $380 \mathrm{~K}$ [4]. 
Knowing the value of the barrier $\left(\bar{E}_{b}=0.41 \mathrm{eV}\right)$ [5], the migration energies $E_{\mathrm{I}}^{m}=0.5 \mathrm{eV}$ and $E_{\mathrm{I}_{2}}^{m}=0.33 \mathrm{eV}$ at the temperature about $100{ }^{\circ} \mathrm{C}$ can be determined. These small migration energies of vacancies and interstitial atoms sometimes were used (without direct experimental evidences) at high temperatures up to the silicon melting point. The experiments on radiation-accelerated selfdiffusion of ${ }^{30} \mathrm{Si}$ to the region of ${ }^{28} \mathrm{Si}(99.926 \%)$ with the thickness $280 \mathrm{~nm}$ were performed, and the migration enthalpy of vacancies $H_{\mathrm{V}}^{m}=(1.8 \pm 0.5) \mathrm{eV}$ within the temperature range $780 \ldots 872{ }^{\circ} \mathrm{C}$ was defined by the authors of [6]. The migration enthalpy of interstitial atoms $H_{\mathrm{I}}^{m}=(1.77 \pm 0.12) \mathrm{eV}$ was determined in [7]. Thus, at low temperature the migrating vacancy is more localized than at high temperatures that confirms the opinion of the authors [8] about the delocalized nature of defects in silicon. The authors of [9] suppose that the thermally-activated movement of interstitial atoms and vacancies in the neutral charge states occurs at temperatures higher than 150 and $175 \mathrm{~K}$, respectively.

Extremely high mobility of $\mathrm{I}_{\mathrm{Si}}$ at the temperatures $T<10 \mathrm{~K}$ appears only in the process of irradiation, and it has no activation character (as a result of sequential recharge of $\mathrm{I}_{\mathrm{Si}}$ ) [10]. The interstitial $\mathrm{Si}$ atoms, according to the Watkins substitution mechanism, crowd out the $\mathrm{C}$, $\mathrm{B}$, In, Al impurities from the lattice points to the interstitial position without the need to overcome the barrier [11]. Herewith, their free path is $10^{-5}-10^{-6} \mathrm{~cm}$. The interstitial atom $\mathrm{I}^{++}$from its tetrahedral $(\mathrm{T})$ position by capturing one electron becomes $\mathrm{I}^{+}$and can moves to the B-position (the configuration centered by bonds). The hole capture will convert it back to $\mathrm{I}^{++}$state, which results in displacing it to T-position again [12].

It is known that the vacancy and interstitial silicon atom have negative correlation energy, which makes energy-favourable changing of charge state of defect from double positive to neutral state directly. The neutral level of vacancy is equal $E_{\mathrm{V}}+0.37 \mathrm{eV}$ [13], therefore the appearance of level $\left(E_{\mathrm{V}}+0.04 \mathrm{eV}\right)^{+/++}$is observed when studying by the EPR method, since the hole generated by photon with energy of $0.35 \mathrm{eV}$ was captured on the neutral level of vacancy. The migration energy of vacancy in double positive charge state $\left(E_{m}=\right.$ $0.32 \pm 0.02 \mathrm{eV}$ ) was determined in [3]. In the case of interstitial silicon atom, the neutral level in the forbidden band of Si should be located at $E_{\mathrm{V}}+0.09 \mathrm{eV}$, because $\mathrm{I}^{-/ 0}$ has the position at $E_{c}-0.70 \mathrm{eV}$ [14]. Thus, the donor levels of $\mathrm{I}_{\mathrm{Si}}$ should be deep in the valence band. Therefore, the positively charged interstitial atoms in silicon $\mathrm{I}_{\mathrm{Si}}$ have not been found up to date. However, irradiation with electrons at the temperature of $4.2 \mathrm{~K}$ in silicon containing $\mathrm{C}, \mathrm{Ga}$, In, Al substitution atoms leads to appearance of vacancies and interstitial ions $\mathrm{Al}^{++}$in approximately equal amounts with the introduction rate of $0.03 \mathrm{~cm}^{-1}$ at the Rutherford scattering of electrons.
Apparently, the EPR signal for interstitial silicon atom does not occur, since $\mathrm{I}_{\mathrm{Si}}^{-/ 0}$ is in the zero-charge state in this experiment. The crowdion and dumbbell configuration can be formed by embedding the incuse atom into the chain of crystal atoms. Herewith, the consistent shift of chain atoms will take place [5]. In other words, the deformation wave along the chain of atoms ("the tsunami wave") will extend. When the wave reaches the atom that has the covalent radius different from the one of silicon atoms, then the wave energy is spent on pushing this atom out the lattice point. Since the deformation field around this atom spreads on a distance of about three or four lattice parameters, the vacancy will be located at this distance from the interstitial ion $\mathrm{Al}^{++}$, but not in the immediate vicinity to him. It is very likely that both vacancy and interstitial silicon atoms in the crystal lattice can move only using the activation way, and the migration energy depends not only on the charge state, but also on the localization of the defect in the lattice.

\section{Results and discussion}

To restore the electrophysical and optical properties of semiconductor materials and devices based on them, the annealing of radiation defects created by nuclear radiation is commonly used. In addition to migration of defects to the sinks and their dissociation, it must be taken into account the annealing of vacancy-type defects with interstitial and di-interstitial atoms. When the concentration of defects in solids exceeds the equilibrium level at a given temperature, then, under appropriate conditions, these defects will interact not only with each other but also with background impurities and thus will reduce the free energy of the crystal. The annealing can be described as equations similar to those used in the chemical kinetics.

Accumulation or disappearance of the concentration of defects $P$ caused by the annealing process of the first order can be defined through the constants of rate $K$ :

$$
\frac{d P^{i}}{d t}+K_{i}\left(P^{i}-P_{m}^{i}\right)=0, \quad \frac{d P^{j}}{d t}=-K_{j} P^{j} .
$$

It should be noted that the use of first-order kinetics is valid in the case, when the concentration of sinks is at least an order of magnitude greater than the concentration of radiation defects [15]. Usually the rate constant is equal $K_{i, j}=A^{i, j} \exp \left(-E_{a}^{i, j} / k T\right)$, where $A^{i, j}$ are the frequency factors; $E_{a}^{i, j}$ are the activation energies of processes; $k$ is the Boltzmann constant; $T$ is an absolute temperature; $j, i$ is the number of channels for annealing and accumulation of defects, respectively.

Integrating the equation (1) and adding the various channels of annealing or accumulation of defects, one can obtain the following approximation 


$$
\begin{aligned}
& P(T)=\sum_{j=1}^{k} P_{0}^{j} \exp \left[-A^{j} t \exp \left(-E_{a}^{j} / k T\right)\right]+ \\
& +\sum_{i=1}^{m} P_{m}^{i}\left[1-\exp \left(-A^{i} t \exp \left(-E_{a}^{i} / k T\right)\right)\right]-\sum_{l=1}^{n} P_{00}^{l},
\end{aligned}
$$

at the condition that $P(200 \mathrm{~K})=1.0$ in relative units. The latter term $P_{00}^{l}$ is related with the fact that the annealing process is not completed. Here $P_{0}^{j}$ is the share of annealing of defect concentration in $j$-manner; $P_{m}^{i}$ is the share of accumulation of defect concentration in $i$-manner; $t$ is the annealing time. The more stable defect can be formed, for example, by the annealing of another defect. Interstitial silicon atoms movable at room temperature can anneal not only A-centers but also divacancies. The change in rates of concentrations inherent to vacancies and $\mathrm{A}$ - centers are equal

$$
\frac{d[\mathrm{~V}]}{d t}=\frac{[\mathrm{I}]}{\tau_{a}}-\frac{[\mathrm{V}]}{\tau_{b}}, \quad \frac{d\left[\mathrm{VO}_{i}\right]}{d t}=\frac{[\mathrm{V}]}{\tau_{b}},
$$

where

$$
\tau_{a}=\frac{1}{v_{a}}=\frac{1}{v_{a}^{0}} \exp \left(\frac{E_{a}}{k T}\right) \text { and } \tau_{b}=\frac{1}{v_{b}}=\frac{1}{v_{b}^{0}} \exp \left(\frac{E_{b}}{k T}\right)
$$

are the lifetimes of interstitial atom and vacancy, respectively, up to the capture by di-vacancy and interstitial oxygen; [V], [I], [ $\left.\mathrm{VO}_{\mathrm{i}}\right]$ are the concentrations of vacancies, interstitial atoms, and $\mathrm{A}$-centers, respectively; $v_{a}^{0}, v_{b}^{0}$ are the frequency pre-exponential factors; $E_{a}, E_{b}$ are the activation energy of divacancy annealing and the activation energy of A-center formation, respectively.

The solutions of Eqs (3) are the functions of the annealing temperature $T$. The change in the concentration of A-centers as dependent on the annealing temperature (which entering into the formulas for $v_{a}$ and $v_{b}$ ) of the irradiated silicon is equal

$$
\begin{aligned}
& {\left[\mathrm{VO}_{i}\right]=\left[\mathrm{I}_{0}\right]\left(v_{a}\left[1-\exp \left(-v_{b} t\right)\right]-\right.} \\
& \left.-v_{b}\left[1-\exp \left(-v_{a} t\right)\right]\right) /\left(v_{a}-v_{b}\right) .
\end{aligned}
$$

Changing of the concentration of vacancies depending on the temperature of annealing of irradiated silicon is equal

$$
[\mathrm{V}]=\left[\mathrm{I}_{0}\right] v_{a}\left[\exp \left(-v_{a} t\right)-\exp \left(-v_{b} t\right)\right] /\left(v_{b}-v_{a}\right),
$$

where $\left[\mathrm{I}_{0}\right]$ is the initial concentration of interstitial silicon atoms.

The obtained equations (1)-(5) can be applied to describe the isochronal annealing of $\mathrm{A}$ - centers by using the experimental data of R.E. Whan [16]. In this work, after irradiation of $\mathrm{n}-\mathrm{Si}$ grown by Czochralski $(\mathrm{Cz})$ with $2 \mathrm{MeV}$ electrons at the temperature close to $-50^{\circ} \mathrm{C}$ with the fluence $1 \times 10^{18} \mathrm{~cm}^{-2}$ and after annealing step by $25^{\circ} \mathrm{C}$ during $20 \mathrm{~min}$, the vibration band at $836 \mathrm{~cm}^{-1}$ at $80 \mathrm{~K}$ was measured. The samples of $\mathrm{n}-\mathrm{Si}$ with specific resistance of 10 and $100 \mathrm{Ohm} \cdot \mathrm{cm}$, doped with phosphorus, contain about $7 \times 10^{17} \mathrm{~cm}^{-3}$ of interstitial oxygen atoms. The oxygen-vacancy complex (A-center) is one of the main radiation defects in silicon. When capturing the vacancy, the oxygen atom is shifted and, filling it, is located almost in the vacant lattice point. The results of the uniaxial compression show that the energy of atomic reorientation of $\mathrm{A}$ - center is about $0.38 \mathrm{eV}$ [17] and reorientation can occur at room temperature. A - center has six possible orientations in the silicon lattice. Oxygen is displaced from the center of tetrahedral substitutional position in the line of $\langle 100\rangle$ and linked with two silicon atoms, forming the $\mathrm{Si}-\mathrm{O}_{\mathrm{i}} \mathrm{-Si}$ bonds. Thus, A-center has no dangling bonds. Two vibrational absorption bands correspond to A - center: $830 \mathrm{~cm}^{-1}$ (in the state of $\mathrm{VO}^{0}$ ) and $877 \mathrm{~cm}^{-1}$ (in the state of $\mathrm{VO}^{-}$) when measuring at room temperature. The band at $889 \mathrm{~cm}^{-1}\left(\mathrm{VO}_{2 \mathrm{i}}\right)$ grows with the activation energy of $E_{a}=1.86 \mathrm{eV}$ and the frequency factor $v=6 \times 10^{11} \mathrm{~s}^{-1}$ [18].

As reported in [19], there observed is simultaneous appearance of two defects with levels in the silicon forbidden band $E_{\mathrm{V}}+0.35 \mathrm{eV}$ and $E_{\mathrm{V}}+0.38 \mathrm{eV}$ during the annealing of $\mathrm{C}_{\mathrm{i}}$ - centers. The first level is not stable at room temperature, and its disappearance is accompanied by a further increase of the concentration of $\mathrm{C}_{\mathrm{i}} \mathrm{O}_{\mathrm{i}}$-defects with the level of $E_{\mathrm{V}}+0.38 \mathrm{eV}$. Interstitial carbon defect arises as a product of the interaction between the silicon atom and substitutional carbon $\left(\mathrm{C}_{\mathrm{s}}\right)$ by the capture mechanism [20]. In the first configuration, $\mathrm{C}$ and $\mathrm{Si}$ atoms are placed along the $\langle 001\rangle$ direction, occupying the vacant lattice point of silicon. This configuration is the most stable one for $\mathrm{C}_{\mathrm{i}}$ in silicon. The reaction of $\mathrm{C}_{\mathrm{s}}+\mathrm{I}_{\mathrm{Si}} \rightarrow \mathrm{C}_{\mathrm{i}}$ is considered as exothermic reaction with the release of $1.2 \mathrm{eV}$ energy. Therefore, carbon shifts from the lattice point into the interstitial position and moves in the silicon lattice with the energy $E_{m}=0.87 \mathrm{eV}$. This $\mathrm{C}_{\mathrm{i}}$ configuration interacts with $\mathrm{O}_{\mathrm{i}}$ that immediately occupies a vacant lattice point, forming $\mathrm{C}_{\mathrm{i}} \mathrm{VO}_{\mathrm{i}} \mathrm{I}_{\mathrm{Si}}$-defect $\left(E_{\mathrm{V}}+0.35 \mathrm{eV}\right)$. At room temperature, this defect is not stable, since $\mathrm{I}_{\mathrm{Si}}$ leaves to sinks, forming, in our opinion, $\mathrm{C}_{\mathrm{i}} \mathrm{VO}_{\mathrm{i}}$-defect $\left(E_{\mathrm{V}}+0.38 \mathrm{eV}\right)$. The increase in energy of the $\mathrm{C}_{\mathrm{i}} \mathrm{VO}_{\mathrm{i}}$ donor defect by $0.03 \mathrm{eV}$ indicates that it is $\mathrm{I}_{\mathrm{Si}}$ that leaves to sinks at room temperature [21]. $\mathrm{C}_{\mathrm{i}}$ in the interstitial position interacts with $\mathrm{O}_{\mathrm{i}}$ with the activation energy $0.87 \mathrm{eV}$ corresponding to this process, forming $(\mathrm{CO})_{\mathrm{i}}$-defect with the energy position $E_{\mathrm{V}}+0.34 \mathrm{eV}$ [22]. However, the activation energy during the interaction with $\mathrm{A}$-centers decreases down to $0.77 \mathrm{eV}$, since the barrier of $\mathrm{C}_{\mathrm{i}}$ interaction with $\mathrm{VO}_{\mathrm{i}}$ is less than that with $\mathrm{O}_{\mathrm{i}}$.

Fig. 1 shows the isochronal annealing of A - centers described using Eq. (2) and nine channels of accumulation and disappearance of the vibrational band at $836 \mathrm{~cm}^{-1}$. 


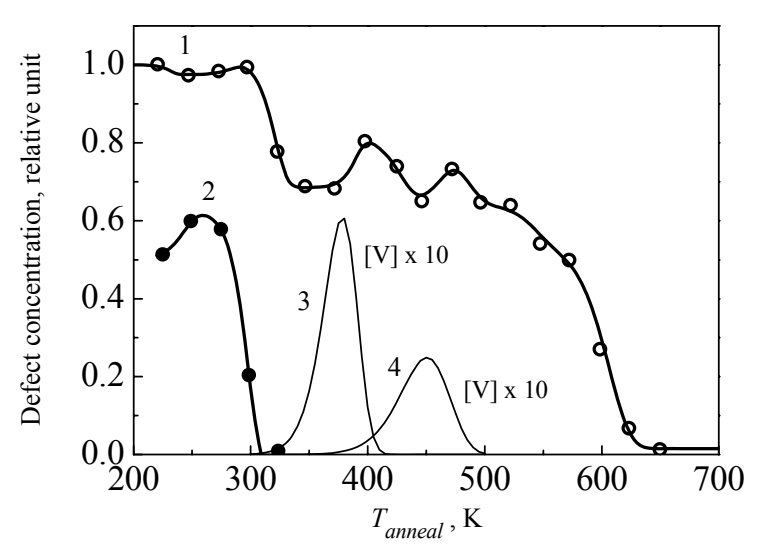

Fig. 1. Calculation of the isochronal annealing of defects in the electron-irradiated Cz-Si: 1 - A-centers (VO), $836 \mathrm{~cm}^{-1} ; 2$ $\mathrm{C}_{\mathrm{i}}$-centers (interstitial carbon), $922 \mathrm{~cm}^{-1} ; 0, \bullet-$ the experimental data obtained in [16]; — - the theoretical description made by the authors of this paper; 3 and $4-$ the calculated dependences of vacancy generation (V) as consistent with reactions $\mathrm{V}_{3}+\mathrm{I}_{2} \rightarrow \mathrm{V}$ and $\mathrm{V}_{2}+\mathrm{I} \rightarrow \mathrm{V}$, respectively, and annealing $\mathrm{V}+\mathrm{O}=\mathrm{VO}$.

Parameters for calculations and the reaction types for accumulation and annealing of A-centers are presented in Table 1, in which $E_{a}$ and $v$ are the activation energy of accumulation and disappearance of A - centers and their frequency factor; $h$ is the concentration of defects on different stages of annealing in relative units; $N_{0}$ is the concentration of sinks; $\bar{T}$ is the temperature of center for annealing stage; $D_{0}$ is the pre-exponential factor of the diffusion coefficient of the mobile defect; $R$ is the radius of capturing the mobile defect by $\mathrm{A}$ - center at the temperature of center at the annealing stage.
As seen from Table 1, accumulation of A - centers occurred in three temperature ranges. In the interval of $250-300 \mathrm{~K}$, the migration energy of Frenkel pair is similar to the migration energy of vacancy [2]. It can be assumed that dissociation of Frenkel pairs occurs in the vicinity of $\mathrm{O}_{\mathrm{i}}$. Second $300-400 \mathrm{~K}$ and third $350-500 \mathrm{~K}$ stages of $\mathrm{A}$-centers accumulation are described by Eq. (4). Concentrations of vacancies captured by $\mathrm{O}_{\mathrm{i}}$ are presented as curves 3 and 4 in Fig. 1 . They were determined using Eq. (5). In these stages the generation of vacancies is a process of annealing of $\mathrm{V}_{3}$ and $\mathrm{V}_{2}$ defects during the capture of $\mathrm{I}_{2}$ and I, respectively.

As seen from Table 1, the annealing of A-centers occurs by capturing the di-interstitial and interstitial atoms of silicon, as well as the oxygen dimer. Moreover, A-center can be reorientated during the capture of interstitial atom. Then the activation energy of $\mathrm{VO}_{\mathrm{i}}$ annealing will increase up to $1.3 \mathrm{eV}$. Naturally, in $\mathrm{n}-\mathrm{Si}$ grown using the Czochralski method, the free oxygen atoms $\left(\mathrm{O}_{\mathrm{i}}\right)$ are the main sinks, but in the vicinity of $500 \mathrm{~K}$ the deformation fields reduce the migration energy of A - centers on sinks down to $E_{a}=1.5 \mathrm{eV}$. It is possible that within this range clustering the vacancytype defects occurs.

Thus, made in the work [1] suggestion that within the range of annealing temperatures $300-400{ }^{\circ} \mathrm{C}$ dissociation of A-centers occurs was not confirmed. More likely that A-center only partially dissociates in the course of migration to the $\operatorname{sink}\left(\mathrm{O}_{\mathrm{i}}\right)$ with formation of $\mathrm{VO}_{2 \mathrm{i}}$-defect (the band of $889 \mathrm{~cm}^{-1}$ ). It was showed in [23] that the capture radius of carbon by the interstitial atom of oxygen was equal to $R=17 \AA$. After revision of the oxygen contents in $\mathrm{Cz}-\mathrm{Si}$ [24], the capture radius is

Table 1. Parameters of the isochronal annealing of $C_{i}$ and A-centers in the electron-irradiated $\mathrm{Cz}-\mathrm{Si}$ (the experimental data obtained by R.E. Whan [16]).

\begin{tabular}{|c|c|c|c|c|c|c|c|c|}
\hline Procedure & Reaction & $\begin{array}{l}E_{a} \\
e V\end{array}$ & $v, s^{-1}$ & $\begin{array}{c}h, \\
\text { relative } \\
\text { unit }\end{array}$ & $\begin{array}{c}\bar{N}_{\mathrm{O}_{\mathrm{i}}, \mathrm{VO}_{\mathrm{i}}, \mathrm{C}_{\mathrm{i}}} \\
\mathrm{cm}^{-3}\end{array}$ & $D_{0}, \mathrm{~cm}^{2} / \mathrm{s}$ & $\bar{T}, \mathrm{~K}$ & $R, \AA$ \\
\hline \multirow{3}{*}{$\begin{array}{c}\text { Formation of } \\
\text { A-centers, } \\
836 \mathrm{~cm}^{-1}\end{array}$} & $\mathrm{~V}+\mathrm{O}_{\mathrm{i}} \rightarrow \mathrm{VO}_{\mathrm{i}}$ & 0.8 & $7 \times 10^{10}$ & 0.035 & $7 \times 10^{17}$ & 0.05 & 282.75 & 16.2 \\
\hline & $\begin{array}{c}\mathrm{I}_{2}+\mathrm{V}_{3} \rightarrow \mathrm{V} \\
\mathrm{V}+\mathrm{O}_{\mathrm{i}} \rightarrow \mathrm{VO}_{\mathrm{i}}\end{array}$ & $\begin{array}{c}0.74 \\
0.8\end{array}$ & $\begin{array}{l}5 \times 10^{6} \\
2 \times 10^{7}\end{array}$ & 0.13 & & & & \\
\hline & $\begin{array}{c}\mathrm{I}+\mathrm{V}_{2} \rightarrow \mathrm{V} \\
\mathrm{V}+\mathrm{O}_{\mathrm{i}} \rightarrow \mathrm{VO}_{\mathrm{i}}\end{array}$ & $\begin{array}{c}0.91 \\
0.8\end{array}$ & $\begin{array}{l}5 \times 10^{6} \\
1 \times 10^{6}\end{array}$ & 0.15 & & & & \\
\hline \multirow{6}{*}{$\begin{array}{l}\text { Annealing of } \\
\text { A-centers, } \\
836 \mathrm{~cm}^{-1}\end{array}$} & $\mathrm{I}_{2}+\mathrm{VO} \rightarrow \mathrm{O}_{\mathrm{i}}+\mathrm{I}$ & 0.74 & $7 \times 10^{12}$ & 0.025 & $3.46 \times 10^{17}$ & 7.89 & 229.37 & 20.4 \\
\hline & $\mathrm{I}+\mathrm{VO}_{\mathrm{i}} \rightarrow \mathrm{O}_{\mathrm{i}}$ & 0.91 & $1 \times 10^{11}$ & 0.325 & $2.97 \times 10^{17}$ & 0.13 & 318.17 & 21.5 \\
\hline & $\mathrm{I}+\stackrel{\leftarrow}{\mathrm{VO}_{\mathrm{i}}} \rightarrow \mathrm{O}_{\mathrm{i}}$ & 1.3 & $1 \times 10^{12}$ & 0.17 & $2.56 \times 10^{17}$ & 1.25 & 425.04 & 24.9 \\
\hline & $\begin{array}{c}\text { Drift in the } \\
\text { deformation field }\end{array}$ & 1.5 & $2 \times 10^{12}$ & 0.15 & & & 481.03 & \\
\hline & $\mathrm{O}_{2 \mathrm{i}}+\mathrm{VO}_{\mathrm{i}} \rightarrow \mathrm{VO}_{3 \mathrm{i}}$ & 1.7 & $3 \times 10^{12}$ & 0.1 & $2.06 \times 10^{17}$ & 4.77 & 539.13 & 24.3 \\
\hline & $\mathrm{VO}_{\mathrm{i}}+\mathrm{O}_{\mathrm{i}} \rightarrow \mathrm{VO}_{2 \mathrm{i}}$ & 1.86 & $1.5 \times 10^{12}$ & 0.53 & $7 \times 10^{17}$ & 1.06 & 601.26 & 16.2 \\
\hline $\begin{array}{c}\text { Annealing of } \\
\mathrm{C}_{\mathrm{i}}, \\
922 \mathrm{~cm}^{-1}\end{array}$ & $\begin{array}{c}\mathrm{I}+\mathrm{C}_{\mathrm{s}} \rightarrow \mathrm{C}_{\mathrm{i}} \\
\mathrm{C}_{\mathrm{i}}+\mathrm{VO}_{\mathrm{i}} \rightarrow \mathrm{C}_{\mathrm{i}} \mathrm{VO}_{\mathrm{i}}\end{array}$ & $\begin{array}{c}0.5 \\
0.77\end{array}$ & $\begin{array}{l}1.7 \times 10^{7} \\
8 \times 10^{9}\end{array}$ & $\begin{array}{l}0.12 \\
0.67\end{array}$ & $\begin{array}{l}3 \times 10^{17} \\
3.5 \times 10^{17}\end{array}$ & $\begin{array}{l}2.15 \times 10^{-5} \\
8.76 \times 10^{-3}\end{array}$ & $\begin{array}{l}240.5 \\
295.5\end{array}$ & $\begin{array}{l}21.5 \\
20.3\end{array}$ \\
\hline
\end{tabular}


equal to $R=14.7 \AA$. The oxygen atom in the interstitial position creates deformation of the silicon lattice, therefore during migration of interstitial carbon toward oxygen, it needs to overcome the potential barrier depending not only on the distance to the oxygen atom, but also on the motion path of carbon. There are three such motion paths: TH, TB, THTB. Here TH is a transition of the interstitial atom from tetrahedral in hexagonal position in the silicon lattice; $\mathrm{TB}$ is a transition of the interstitial atom from tetrahedral in the bond centered position; THTB is a transition from tetrahedral in hexagonal position, then in tetrahedral and in bond centered position.

The experimental data for the metastable complexes of $\mathrm{C}_{\mathrm{i}} \mathrm{O}_{\mathrm{i}}$ are presented in [1]. According to the proposed model [25], the oxygen and carbon atoms do not form the direct bonds, therefore their local vibrational modes can be represented as "oxygenrelated" or "carbon-related". Accumulation and annealing of the concentration of various local vibrational bands were calculated according to Eq. (2) using the experimental data obtained in [24]. The direction of the movement of $\mathrm{C}_{\mathrm{i}}$ to $\mathrm{O}_{\mathrm{i}}$ depends on the value of barrier that should be overcome by $\mathrm{Si}$ atoms when moving to $\mathrm{O}_{\mathrm{i}}$. Herewith, it was taken into account that the deformation field decreases in inverse proportion to the square of the distance from the $\mathrm{O}_{\mathrm{i}}$ atom.

Let us assume that we consider an elastic medium with the center of expansion at the origin of coordinates, where the interstitial oxygen atom is located. It means that under some small radius $r_{0}$ there is the radial displacement of medium $\left(\delta_{0}\right)$. The problem was solved in [26] in approximation of lattice deformation without changing its volume.

The deformation energy is equal to

$U_{\text {def }}=\frac{16}{3} \pi \mu r_{0} \delta_{0}^{2}$

where $\mu=0.63 \mathrm{eV} / \AA^{3}$ is a modulus of elasticity under shift. At positive $\delta_{0}$ (it is expansion) the medium was compressed along the radius and was stretched tangentially.

The radial shift is

$\delta(r)=\left(\frac{r_{0}}{r}\right)^{2} \delta_{0}$.

Parameters for the annealing of precursors for formation of the $\mathrm{C}_{\mathrm{i}} \mathrm{O}_{\mathrm{i}}$ stable defect are presented in Table 2. The activation energies of accumulation and annealing of $\mathrm{C}_{\mathrm{i}} \mathrm{O}_{\mathrm{i}}$ metastable defects were determined, and the directions of $\mathrm{C}_{\mathrm{i}}$ motion were indicated. The value of the potential barrier $\left(E_{b}\right)$ was defined as $E_{b}=E_{a}-E_{m}^{\mathrm{C}_{\mathrm{i}}}$, where $E_{a}$ is the activation energy of $\mathrm{C}_{\mathrm{i}}$ motion; $E_{m}^{\mathrm{C}_{\mathrm{i}}}=0.87 \mathrm{eV}$ is the migration energy of interstitial carbon atoms $\left(\mathrm{C}_{\mathrm{i}}\right)$. The migration energy of $\mathrm{C}_{\mathrm{i}}$ was determined by the annealing of $922.1 \mathrm{~cm}^{-1}$ band (Fig. 2). The temperature of the center stage $(\bar{T})$ and the frequency jumps of $\mathrm{C}_{\mathrm{i}}$ at this temperature were also determined and presented in Table 2, where the concentration of defects was indicated in relative units $(N)$.

On the basis of the determinate barriers for movement of $\mathrm{C}_{\mathrm{i}}$ to $\mathrm{O}_{\mathrm{i}}$, in Fig. 3 we show the schematic model of $\mathrm{C}_{\mathrm{i}} \mathrm{O}_{\mathrm{i}}$ metastable pairs. According to the proposed model, the bands related to III group of precursors in $\mathrm{C}_{\mathrm{i}} \mathrm{O}_{\mathrm{i}}$ formation can be annealed with the activation energy $E_{a}=2.5 \mathrm{eV}$, if the $\mathrm{C}_{\mathrm{i}}$ atom will jump to II group or the $\mathrm{O}_{\mathrm{i}}$ atom will migrate closer to the $\mathrm{C}_{\mathrm{i}}$ atom. Annealing of these bands will also occur if the $\mathrm{C}_{\mathrm{i}}$ atom with the migration energy $E_{m}^{\mathrm{C}_{\mathrm{i}}}=0.87 \mathrm{eV}$ shifts closer to oxygen, which will form herewith one bond more with the silicon atom.

According to this model, the vibrational band of $967.4 \mathrm{~cm}^{-1}$ should be defined as related to two oxygen atoms $\left(\mathrm{O}_{2 \mathrm{i}}\right)$, since only $\mathrm{O}_{2 \mathrm{i}}$ has the migration energy of $E_{m}^{\mathrm{O}_{2 \mathrm{i}}}=1.7 \mathrm{eV}$. From presence of the activation energy of annealing $E_{a}^{\mathrm{C}_{\mathrm{i}}}=0.87 \mathrm{eV}$, the band of $967,4 \mathrm{~cm}^{-1}$ should be related to the III group of precursors for $\mathrm{C}_{\mathrm{i}} \mathrm{O}_{2 \mathrm{i}}$ formation.

The description of the annealing of some bands is presented in Fig. 2. In spite of the fact that the band of $910.1 \mathrm{~cm}^{-1}$ was related to the III group of precursors, in which the $\mathrm{C}_{\mathrm{i}}$ carbon atom is located closest to the $\mathrm{O}_{\mathrm{i}}$ atom, its growth and annealing occurs $30 \mathrm{~K}$ earlier than these for the other precursors of $\mathrm{C}_{\mathrm{i}} \mathrm{O}_{\mathrm{i}}$.

Therefore, it is assumed that this is related with different ways of $\mathrm{C}_{\mathrm{i}}$ motion to $\mathrm{O}_{\mathrm{i}}$. Usually, the vibrational band of $865,9 \mathrm{~cm}^{-1}$ is considered as related to the $\mathrm{C}_{\mathrm{i}} \mathrm{O}_{\mathrm{i}}$ stable defect that is annealed with energy of $E_{a}=1.86 \mathrm{eV}$. Herewith, the $\mathrm{C}_{\mathrm{s}} \mathrm{O}_{\mathrm{i}}$ defect is formed with the activation energy of $1.86 \mathrm{eV}$, and in this region of temperatures the $\mathrm{A}$-centers are also annealed with the migration energy of $E_{m}^{\mathrm{VO}_{\mathrm{i}}}=1.86 \mathrm{eV}$ to the sinks $\left(\mathrm{O}_{\mathrm{i}}\right.$ atoms) with forming the band of $889 \mathrm{~cm}^{-1}$. This band increases with the $\mathrm{VO}_{2}$-defect formation energy equal to $E_{a}=1.86 \mathrm{eV}$ and with the frequency factor equal to $v=6 \times 10^{11} \mathrm{~s}^{-1}$.

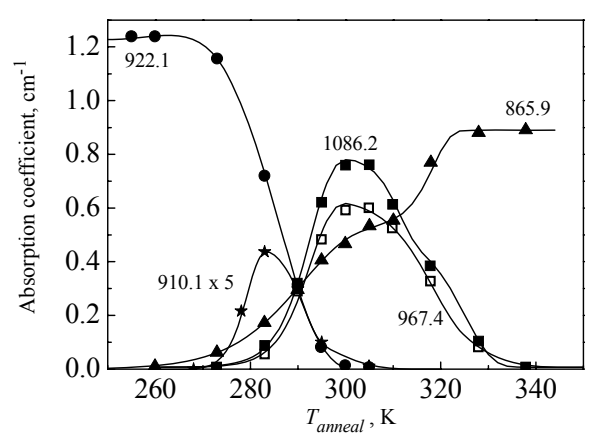

Fig. 2. Calculation of changes in intensities of absorption bands associated with interstitial carbon-related defects upon $20 \mathrm{~min}$ isochronal annealing of electron-irradiated $\mathrm{Cz}-\mathrm{Si}$ samples. $\boldsymbol{\square}, \square, \bullet, \mathbf{\Delta}, \$$ the experimental data obtained in [24]; - the theoretical description made by the authors of this paper. 
Table 2. Parameters of the isochronal annealing of precursors of $\mathrm{C}_{\mathrm{i}} \mathrm{O}_{\mathrm{i}}$-defect formation in the electron-irradiated $\mathrm{Cz}$-Si (the experimental data obtained by L.I. Khirunenko et al. [24]).

\begin{tabular}{|c|c|c|c|c|c|c|}
\hline $\begin{array}{l}\text { Vibrational band } \\
\text { absorption, } \mathrm{cm}^{-1}\end{array}$ & $\begin{array}{l}\text { Motion } \\
\text { of } C_{i}\end{array}$ & $E_{a}, \mathrm{eV}$ & $E_{b}, \mathrm{eV}$ & $\bar{T}, \mathrm{~K}$ & $v_{0} \exp \left(-\frac{E_{b}}{k \bar{T}}\right), \mathrm{s}^{-1}$ & $N$, relative unit \\
\hline \multirow{2}{*}{$1059.6^{\mathrm{O}_{\mathrm{i}}}$} & $\begin{array}{l}\text { to } \mathrm{O}_{\mathrm{i}} \\
\text { from } \mathrm{O}_{\mathrm{i}}\end{array}$ & $\begin{array}{l}1.1 \\
1.7\end{array}$ & $\begin{array}{l}0.23 \\
0.83\end{array}$ & $\begin{array}{c}275.6 \\
286.15\end{array}$ & $\begin{array}{l}4.67 \times 10^{12} \\
1.20 \times 10^{12}\end{array}$ & $\begin{array}{l}0.27 \\
0.13\end{array}$ \\
\hline & to $\mathrm{O}_{\mathrm{i}}$ & 1.7 & 0.83 & 295.64 & $3.90 \times 10^{11}$ & 0.4 \\
\hline \multirow[b]{2}{*}{$885^{C_{i}}$} & to $\mathrm{O}_{\mathrm{i}}$ & 1.1 & 0.23 & 286.0 & $1.24 \times 10^{12}$ & 0.6 \\
\hline & $\begin{array}{l}\text { to } \mathrm{O}_{\mathrm{i}} \\
\text { from } \mathrm{O}_{\mathrm{i}}\end{array}$ & $\begin{array}{l}1.7 \\
1.1\end{array}$ & $\begin{array}{l}0.83 \\
0.23\end{array}$ & $\begin{array}{l}291.19 \\
295.14\end{array}$ & $\begin{array}{l}6.65 \times 10^{11} \\
4.14 \times 10^{11}\end{array}$ & $\begin{array}{l}0.43 \\
0.17\end{array}$ \\
\hline \multirow{2}{*}{$812.2^{\mathrm{C}_{\mathrm{i}}}$} & $\begin{array}{c}\text { from } \mathrm{O}_{\mathrm{i}} \\
\text { to } \mathrm{O}_{\mathrm{i}}\end{array}$ & $\begin{array}{l}1.7 \\
1.1\end{array}$ & $\begin{array}{l}0.83 \\
0.23\end{array}$ & $\begin{array}{l}288.3 \\
294.2\end{array}$ & $\begin{array}{l}9.29 \times 10^{11} \\
4.59 \times 10^{11}\end{array}$ & $\begin{array}{c}0.1 \\
0.11\end{array}$ \\
\hline & $\begin{array}{c}\text { to } \mathrm{O}_{\mathrm{i}} \\
\text { from } \mathrm{O}_{\mathrm{i}}\end{array}$ & $\begin{array}{l}1.7 \\
1.1\end{array}$ & $\begin{array}{l}0.83 \\
0.23\end{array}$ & $\begin{array}{l}311.5 \\
324.2\end{array}$ & $\begin{array}{l}7.45 \times 10^{10} \\
2.13 \times 10^{10}\end{array}$ & $\begin{array}{l}0.12 \\
0.09\end{array}$ \\
\hline \multirow{2}{*}{$1097.3^{\mathrm{O}_{\mathrm{i}}}$} & to $\mathrm{O}_{\mathrm{i}}$ & 1.7 & 0.83 & 275.37 & $4.83 \times 10^{12}$ & 0.195 \\
\hline & to $\mathrm{O}_{\mathrm{i}}$ & 2.5 & 1.63 & 290.9 & $6.92 \times 10^{11}$ & 0.195 \\
\hline \multirow[b]{2}{*}{$1013.6^{\mathrm{C}_{\mathrm{i}}}$} & to $\mathrm{O}_{\mathrm{i}}$ & 1.7 & 0.83 & 279.35 & $2.87 \times 10^{12}$ & 0.17 \\
\hline & $\begin{array}{l}\text { to } \mathrm{O}_{\mathrm{i}} \\
\text { from } \mathrm{O}_{\mathrm{i}}\end{array}$ & $\begin{array}{l}2.5 \\
1.7\end{array}$ & $\begin{array}{l}1.63 \\
0.83\end{array}$ & $\begin{array}{l}293.6 \\
299.8\end{array}$ & $\begin{array}{l}4.93 \times 10^{11} \\
2.45 \times 10^{11}\end{array}$ & $\begin{array}{l}0.07 \\
0.10\end{array}$ \\
\hline \multirow[b]{2}{*}{$1086.2^{\mathrm{C}_{\mathrm{i}}}$} & to $\mathrm{O}_{\mathrm{i}}$ & 1.7 & 0.83 & 291.27 & $6.53 \times 10^{11}$ & 0.79 \\
\hline & $\begin{array}{c}\text { to } \mathrm{O}_{\mathrm{i}} \\
\text { from } \mathrm{O}_{\mathrm{i}}\end{array}$ & $\begin{array}{l}2.5 \\
1.7\end{array}$ & $\begin{array}{l}1.63 \\
0.83\end{array}$ & $\begin{array}{c}310.27 \\
323.6\end{array}$ & $\begin{array}{l}8.35 \times 10^{10} \\
2.13 \times 10^{10}\end{array}$ & $\begin{array}{l}0.29 \\
0.50\end{array}$ \\
\hline \multirow[b]{2}{*}{$967.4^{\mathrm{O}_{2 \mathrm{i}}}$} & to $\mathrm{O}_{2 \mathrm{i}}$ & 1.7 & 0.83 & 291.14 & $6.43 \times 10^{11}$ & 0.65 \\
\hline & $\begin{array}{c}\text { from } \mathrm{O}_{2 \mathrm{i}} \\
\text { to } \mathrm{O}_{2 \mathrm{i}}\end{array}$ & $\begin{array}{c}1.7 \\
0.87\end{array}$ & $\begin{array}{c}0.83 \\
0\end{array}$ & $\begin{array}{c}316.35 \\
319.7\end{array}$ & $\begin{array}{c}4.19 \times 10^{10} \\
3.0 \times 10^{10}\end{array}$ & $\begin{array}{c}0.3 \\
0.35\end{array}$ \\
\hline \multirow[b]{2}{*}{$910.1^{C_{i}}$} & to $\mathrm{O}_{\mathrm{i}}$ & 2.5 & 1.63 & 278.5 & $3.19 \times 10^{12}$ & 0.10 \\
\hline & $\begin{array}{c}\text { from } \mathrm{O}_{\mathrm{i}} \\
\text { to } \mathrm{O}_{\mathrm{i}}\end{array}$ & $\begin{array}{c}2.5 \\
0.87\end{array}$ & $\begin{array}{c}1.63 \\
0\end{array}$ & $\begin{array}{c}290.15 \\
290.5\end{array}$ & $\begin{array}{l}7.31 \times 10^{11} \\
5.0 \times 10^{11}\end{array}$ & $\begin{array}{l}0.06 \\
0.04\end{array}$ \\
\hline \multirow{2}{*}{$942.7^{C_{i}}$} & to $\mathrm{O}_{\mathrm{i}}$ & 2.5 & 1.63 & 278.79 & $3.08 \times 10^{12}$ & 0.055 \\
\hline & from $\mathrm{O}_{\mathrm{i}}$ & 2.5 & 1.63 & 290.21 & $7.41 \times 10^{11}$ & 0.055 \\
\hline $865.9^{\mathrm{C}_{\mathrm{i}} \mathrm{O}_{\mathrm{i}}}$ & & $\begin{array}{c}0.77 \\
2.5\end{array}$ & $\begin{array}{c}0 \\
1.73\end{array}$ & $\begin{array}{c}289.0 \\
317.25\end{array}$ & $\begin{array}{l}1.7 \times 10^{10} \\
9.88 \times 10^{8}\end{array}$ & $\begin{array}{l}0.54 \\
0.35\end{array}$ \\
\hline $922.1^{C_{i}}$ & $e_{\mathrm{I}+\mathrm{C}_{\mathrm{s}} \rightarrow \mathrm{C}_{\mathrm{i}}}$ & $\begin{array}{l}0.91 \\
0.87\end{array}$ & $\begin{array}{c}0.4 \\
0\end{array}$ & 263.7 & $\begin{array}{c}3.4 \times 10^{6} \\
1.65 \times 10^{12}\end{array}$ & $\begin{array}{l}0.16 \\
1.39\end{array}$ \\
\hline
\end{tabular}

Based on data obtained using a magnetic spectrometer in [27], it was found that A-center is the amphoteric defect, and it has not only the acceptor $\left(E_{c}-\right.$ $0.17 \mathrm{eV})$ but also the donor $\left(E_{c}-0.76 \mathrm{eV}\right)$ level. Fig. 4 presents the isochronal annealing within the temperature range $300 \ldots 800 \mathrm{~K}$ of $\mathrm{p}-\mathrm{Si}\langle\mathrm{Ge}\rangle\left(p_{0}=1.05 \times 10^{14} \mathrm{~cm}^{-3}\right)$, doped with $1 \%$ of germanium, after irradiation on WWR-M reactor by the fluence $\Phi=1.7 \times 10^{13} \mathrm{n}^{0} \cdot \mathrm{cm}^{-2}$ of fast neutrons at room temperature. The Fermi level position in such samples is $E_{\mathrm{v}}+0.3 \mathrm{eV}$. Thus, we can observe only the annealing of defects that are located above this level. On the curve of annealing of effective carrier concentration (Fig. 4), experimentally obtained by us, three stages of changes in the concentration of holes in the valence band of $\mathrm{p}-\mathrm{Si}$ were found, and one of these stages shows the annealing of donor level of A - center.

At the first stage $\left(T_{a n n}=50 \ldots 300^{\circ} \mathrm{C}\right)$, the defect, possibly $\mathrm{I}_{2}^{+}\left(E_{m}=0.6 \ldots 0.2 \mathrm{eV}[28]\right)$, is annealed with parameters $v=20 \mathrm{~s}^{-1}$ and $E_{a}=0.4 \mathrm{eV}$. If it is $\mathrm{I}_{2}^{+}$ $\left(E_{\mathrm{v}}+0.45 \mathrm{eV}\right)$, then germanium lowers the migration energy of this defect. It may be also joining the divacancies in the form of a tetravacancy. The second stage of annealing has parameters $E_{a}=1.86 \mathrm{eV}$ and $v=2 \times 10^{12} \mathrm{~s}^{-1}$, and it is observed within the temperature range of $T_{a n n}=300 \ldots 320^{\circ} \mathrm{C}$. Since both the energy of this process and the temperature range of annealing are related to A - center, moreover, we study the samples of the very $\mathrm{p}-\mathrm{Si}$, then, in our opinion, Fig. 4 shows the annealing of the donor level of A - center. The third stage of annealing within the temperature range $320 \ldots 500^{\circ} \mathrm{C}$ is formed with the following parameters: $E_{a}=1.5 \mathrm{eV}$ and $v=1.5 \times 10^{7} \mathrm{~s}^{-1}$. Up to date, it is not clear exactly what the defect is annealed in this area.

The description of the annealing of $866 \mathrm{~cm}^{-1}\left(\mathrm{C}_{\mathrm{i}} \mathrm{O}_{\mathrm{i}}\right)$ and $836 \mathrm{~cm}^{-1}$ (VO) bands and the growth of $1104 \mathrm{~cm}^{-1}\left(\mathrm{C}_{\mathrm{s}} \mathrm{O}_{\mathrm{i}}\right)$ band is presented in Fig. 5 according to the experimental data [29] obtained for $\mathrm{Cz}-\mathrm{Si}$ irradiated with $2.5-\mathrm{MeV}$ electrons at room temperature with the fluence $1 \times 10^{18} \mathrm{~cm}^{-2}$. The energy of dissociation or formation of defect is determined by the 
binding energy of components plus the migration energy of a mobile defect. Such mobile defects in this case are vacancy or interstitial carbon atoms $\left(\mathrm{C}_{\mathrm{i}}\right)$. We were lucky in this case: within the range of temperatures close to $550 \mathrm{~K}$ (Fig. 5) the formation stage of $\mathrm{C}_{\mathrm{i}} \mathrm{O}_{\mathrm{i}}$ and $\mathrm{VO}_{\mathrm{i}}$ is observed. Our calculation showed that the migration energy of $\mathrm{C}_{\mathrm{i}}$ within this temperature range is equal to $E_{m}^{\mathrm{C}_{\mathrm{i}}}=1.16 \mathrm{eV}$, and the migration energy of vacancy $E_{m}^{\mathrm{V}}=1.1 \mathrm{eV}$.

Thus, in comparison with the migration energies of $\mathrm{C}_{\mathrm{i}}$ and $\mathrm{I}_{\mathrm{Si}}$ at room temperature, their energy of migration increases by $0.3 \mathrm{eV}$ under $T \sim 550 \mathrm{~K}$, confirming the model that determines the migration energy of defect depending on the degree of delocalization of this defect [8]. In this case, most likely the defects exist in the neutral charge state. The most interesting is that the same concentration of vacancies and interstitial carbon atoms is generated. Thus, one can assume that in this temperature range dissociation of di-vacancy modified by the stable $\mathrm{I}_{\mathrm{Si}} \mathrm{C}_{\mathrm{i}}$ defect occurs in accord with the reaction of $\mathrm{V}_{2} \mathrm{I}_{\mathrm{Si}} \mathrm{C}_{\mathrm{i}} \rightarrow \mathrm{V}+\mathrm{C}_{\mathrm{i}}$.

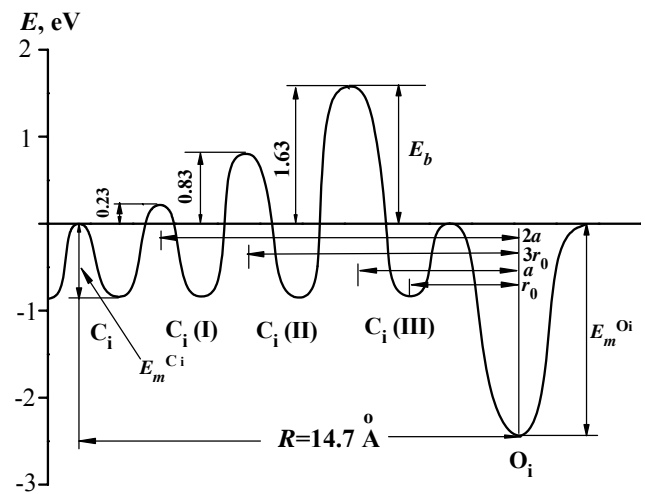

Fig. 3. Schematic model of $\mathrm{C}_{\mathrm{i}} \mathrm{O}_{\mathrm{i}}$ metastable pair. $E_{b}$ is the energy of deformation barrier around $\mathrm{O}_{\mathrm{i}} ; E_{m}$ - the migration energy; $E_{a}=E_{m}+E_{b}$ - the energy of motion activation; $r_{0} \approx 2.35 \AA-$ the minimum distance between atoms; $a \approx 5.43 \AA$ - the lattice parameter of silicon.

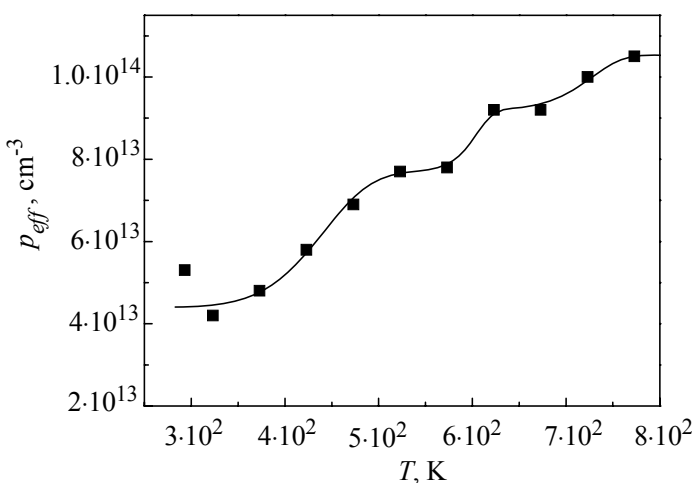

Fig. 4. Dependence of the effective concentration of holes on the temperature of annealing for $\mathrm{p}-\mathrm{Si}\langle\mathrm{Ge}\rangle(\sim 1 \%) \quad\left(p_{0}=\right.$ $=1.05 \times 10^{14} \mathrm{~cm}^{-3}$ ) after irradiation by the fluence $\Phi=$ $=1.7 \times 10^{13} \mathrm{n}^{0} \mathrm{~cm}^{-2}$ of fast-pile neutrons. The isochronous annealing was carried out for $25 \mathrm{~min}$ within the temperature interval 300 to $800 \mathrm{~K}$

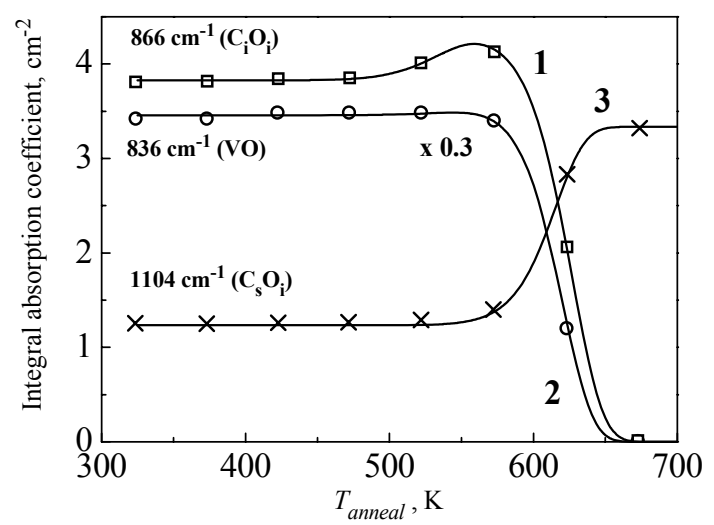

Fig. 5. Changes in the integrated absorption intensity of the bands due to $\mathrm{VO}, \mathrm{C}_{\mathrm{i}} \mathrm{O}_{\mathrm{i}}$ and $\mathrm{C}_{\mathrm{s}} \mathrm{O}_{\mathrm{i}}$ complexes upon isochronal (30 min) annealing of a $\mathrm{Cz}-\mathrm{Si}$ sample $\left(\left[{ }^{16} \mathrm{O}\right]=1.05 \times 10^{18}\right.$, $\left.\left[{ }^{12} \mathrm{C}\right]=3 \times 10^{17} \mathrm{~cm}^{-3}\right)$, electron irradiated $\left(1 \times 10^{18} \mathrm{~cm}^{-2}\right)$ at room temperature. $\square, \circ, \times-$ the experimental data obtained in [29]; - - the theoretical description made by the authors of this paper.

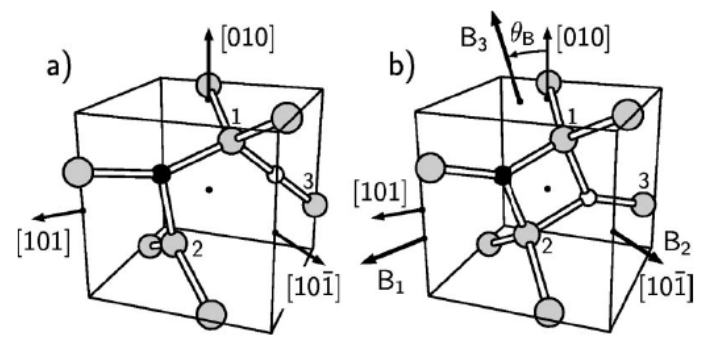

Fig. 6. Models for $\mathrm{C}_{\mathrm{i}} \mathrm{O}_{\mathrm{i}}$ [1]. (a) Divalent oxygen model, $(b)$ trivalent oxygen model. Gray, black, white atoms are $\mathrm{Si}, \mathrm{C}, \mathrm{O}$. Crystallographic axes and principal directions of the $\mathrm{B}$ tensor are also shown.

The calculation of the kinetics of formation of $865.9 \mathrm{~cm}^{-1}$ vibrational band showed that in the temperature region of $250-310 \mathrm{~K}$ the process passed with the activation energy $E_{a}=0.77 \mathrm{eV}$, and within the temperature region 310 to $330 \mathrm{~K}$ with the activation energy $E_{a}=2.5 \mathrm{eV}$. The latter process can be explained as the movement of the interstitial atom $\mathrm{O}_{\mathrm{i}}$ to the vacancy that is left by the carbon atom: $\mathrm{C}_{\mathrm{s}} \mathrm{O}_{\mathrm{i}} \rightarrow \mathrm{C}_{\mathrm{i}} \mathrm{VO}_{\mathrm{i}}$. It is the interstitial atom $\mathrm{O}_{\mathrm{i}}$ that has the activation energy of diffusion in silicon equal to $2.5 \mathrm{eV}$. The band of $1086.2 \mathrm{~cm}^{-1}$ has also the activation energy of annealing $E_{a}=2.5 \mathrm{eV}$, but it is found in the II group, therefore only the movement of $\mathrm{O}_{\mathrm{i}}$ to $\mathrm{C}_{\mathrm{i}}$ can be responsible for this stage of $\mathrm{C}_{\mathrm{i}} \mathrm{O}_{\mathrm{i}}$ formation. And formation of $\mathrm{C}_{\mathrm{i}} \mathrm{O}_{\mathrm{i}}$ with the activation energy of $0.77 \mathrm{eV}$ begins at the temperature close to $250 \mathrm{~K}$, when the precursors are absent yet. Therefore, it is more probable that carbon modifies A-center with formation of the vibrational band at $865.9 \mathrm{~cm}^{-1}$ and with the donor level location in the forbidden band at $E_{\mathrm{V}}+0.38 \mathrm{eV}$ [19]. The authors of [30], using DLTS-measurements, related the donor level $E_{\mathrm{V}}+0.38 \mathrm{eV}$ with the $\mathrm{C}-\mathrm{VO}$ complex. According to the 
model of modification of the donor and acceptor levels of radiation defects by the background impurities such as $\mathrm{C}_{\mathrm{i}}$ and $\mathrm{O}_{\mathrm{i}}$, in the work [14] it was showed that the interstitial carbon increases the energy of acceptor levels in the silicon forbidden band and reduces the energy of donor levels by $0.035 \mathrm{eV}$. Therefore, the donor level of A-center in silicon will be the level of $(0 /+)$ $E_{\mathrm{V}}+0.415 \mathrm{eV}\left(E_{\mathrm{V}}+0.38+0.035 \mathrm{eV}=E_{\mathrm{V}}+0.415 \mathrm{eV}\right)$, and the donor level of $\mathrm{C}_{\mathrm{i}} \mathrm{O}_{\mathrm{i}}$ will be $E_{\mathrm{V}}+0.34 \mathrm{eV}$ and of $\mathrm{C}_{\mathrm{i}} \mathrm{O}_{2 \mathrm{i}}-E_{\mathrm{V}}+0.39 \mathrm{eV}$, as indicated in [31]. In this case, the $\mathrm{C}_{\mathrm{i}}$ carbon atom in the temperature range of $550 \mathrm{~K}$ pushes out $\mathrm{O}_{\mathrm{i}}$ into the interstitial position, overcoming the barrier of $E_{b}=1.86-1.16=0.7 \mathrm{eV}$, and forms the $\mathrm{C}_{\mathrm{s}} \mathrm{O}_{\mathrm{i}}$ defect.

It is known [32] that under irradiation the stable defect of $\mathrm{C}_{\mathrm{i}} \mathrm{I}_{\mathrm{Si}}$ is formed and can be captured by the interstitial oxygen; herewith $\mathrm{C}_{\mathrm{i}}$ and $\mathrm{I}_{\mathrm{Si}}$ in the $\mathrm{C}_{\mathrm{i}} \mathrm{I}_{\mathrm{Si}}$ defect occupy a vacant lattice point in silicon. Then, the reaction of $\mathrm{C}_{\mathrm{i}} \mathrm{I}_{\mathrm{Si}}+\mathrm{O}_{\mathrm{i}} \rightarrow \mathrm{C}_{\mathrm{i}} \mathrm{VO}_{\mathrm{i}}+\mathrm{I}_{\mathrm{Si}}$ will occur within the temperature range 310 to $330 \mathrm{~K}$, moreover the oxygen atom with the migration energy of $E_{m}^{\mathrm{O}_{\mathrm{i}}}=2.5 \mathrm{eV}$ initiates this reaction.

According to the simulation results carried out in [24], the lowest binding energy of $\mathrm{C}_{\mathrm{i}}$ and $\mathrm{O}_{\mathrm{i}}$ within the metastable $\mathrm{C}_{\mathrm{i}} \mathrm{O}_{\mathrm{i}}$ complex related to the III group is equal to $0.7 \mathrm{eV}$. This energy results in a tangential displacement of $\mathrm{Si}_{1}$ and $\mathrm{Si}_{2}$ atoms as shown in Fig. 6 [1]. On the assumption that $\mathrm{C}_{\mathrm{i}}$ and $\mathrm{O}_{\mathrm{i}}$ atoms are found at the distance $r_{0} \approx 2.35 \AA$ from each other, the tangential displacement $\delta_{0}=0.17 \AA$ is equal to the radial one, where the $\mathrm{C}_{\mathrm{i}}$ atom overcomes the barriers. According to the expressions (6) and (7), the distances of $\mathrm{C}_{\mathrm{i}}$ atom from $\mathrm{O}_{\mathrm{i}}$ in the moments when $\mathrm{C}_{\mathrm{i}}$ atom overcomes the barriers determined by us are calculated (Table 2 ). The first and third barriers are found at a distance from oxygen, equal two and one lattice parameter of silicon, respectively. The second barrier $(0.83 \mathrm{eV})$ is located at the distance of three minimum distances $\left(3 r_{0}\right)$ between atoms in the silicon lattice.

\section{Conclusions}

The A-centers (VO) annealing and transformation of precursors for formation of the stable $\mathrm{C}_{\mathrm{i}} \mathrm{O}_{\mathrm{i}}$ defect during the annealing are described. The distance between the interstitial atoms of carbon $\left(\mathrm{C}_{\mathrm{i}}\right)$ and oxygen $\left(\mathrm{O}_{\mathrm{i}}\right)$ at the moments when carbon overcomes the barriers during its migration inside the volume of the radius $(14.7 \AA)$ for capturing $\mathrm{C}_{\mathrm{i}}$ by the atom $\mathrm{O}_{\mathrm{i}}$ has been determined. From the description of the A-center formation in the annealing process, it has been experimentally found that the migration energy of vacancies $\left(E_{\mathrm{V}}^{m}=0.8 \mathrm{eV}\right.$ at $\sim 380 \mathrm{~K}$ and $E_{\mathrm{V}}^{m}=1.10 \mathrm{eV}$ at $\sim 550 \mathrm{~K}$ ) and for the interstitial carbon $\left(E_{m}^{\mathrm{C}_{\mathrm{i}}}=0.87 \mathrm{eV}\right.$ at $280 \mathrm{~K}$ and $E_{m}^{\mathrm{C}_{\mathrm{i}}}=1.16 \mathrm{eV}$ at $520 \mathrm{~K}$ ) in the silicon lattice depends on temperature. It is shown that long-range migration of self-interstitial silicon atoms at $T<10 \mathrm{~K}$ can not be realized under irradiation, because the levels of interstitials atoms in a positive and twice positive charged states are deeply located in the valence band.

\section{References}

1. J. Coutinho, R. Jones, P.R. Briddon, S. Öberg, L.I. Murin, V.P. Markevich, J.L. Lindström, Interstitial carbon-oxygen center and hydrogen related shallow thermal donors in $\mathrm{Si} / /$ Phys. Rev. B 65, 014109-11 (2001).

2. M. Suezawa, Y. Takada, T. Tamano, R. Taniguchi, F. Hori, and R. Oshima, Migration energies of point defects during electron irradiation of hydrogenated Si crystals // Phys. Rev. B 66, 155201-6 (2002).

3. G.D. Watkins, J.R. Troxell, A.P. Chatterjee, Vacancies and interstitials in silicon // Proc. Intern. Conf. "Defects and Radiation Effects in Semiconductors”. Ser. №46 (Nice, 1978). Inst. of Phys. Bristol and London, p. 16-30, 1979.

4. M.D. Varentsov, G.P. Gaidar, A.P. Dolgolenko, P.G. Litovchenko, The radiation hardness of silicon doped by germanium with high concentration of free oxygen // Nuclear Physics and Atomic Energy 1 (17), p. 60-66 (2006).

5. V.L. Vinetsii, G.A. Kholodar, Radiation Physics of Semiconductors. Naukova dumka, Kiev, p. 200, 1979 (in Russian).

6. H. Bracht, J.F. Pedersen, N. Zangenberg, A.N. Larsen, E.E. Haller, G. Lulli, and M. Posselt, Radiation enhanced silicon self-diffusion and the silicon vacancy at high temperatures // Phys. Rev. Lett. 91 (24), 245502-4 (2003).

7. H. Bracht, N.A. Stolwijk, and H. Mehrer, Properties of intrinsic point defects in silicon determined by zinc diffusion experiments under non-equilibrium conditions // Phys. Rev. B 52 (23), p. $16542-16560$ (1995).

8. A. Seeger and K.P. Chik, Diffusion mechanisms and point defects in silicon and germanium // Phys. status solidi (b) 29 (2), p. 455-542 (1968).

9. P. Partyka, Y. Zhong, K. Nordlund, R.S. Averback, I.M. Robinson, P. Ehrhart, Grazing incidence diffuse X-ray scattering investigation of the properties of irradiation-induced point defects in silicon // Phys. Rev. B. 64, 235207-8 (2001).

10. A. Seeger, H. Foll, W. Frank, Self-interstitials, vacancies and their clusters in silicon and germanium // Proc. Intern. Conf. "Radiation Effects in Semiconductors”. Ser. № 31 (Dubrovnic, 1976). Inst. of Phys. London and Bristol, p. 12-29, 1977.

11. Y. Tokuyama, M. Suezawa, and N. Fukata, T. Taishi and K. Hoshikawa, Occupation site change of self-interstitials and group-III acceptors in Si crystals: Dopant dependence of the Watkins 
replacement efficiency // Phys. Rev. B 69, 125217 7 (2004).

12. R. Car, P.J. Kelly, A. Oshiyama, and S.T. Pantelides, Microscopic theory of atomic diffusion mechanisms in silicon // Phys. Rev. Lett. 52 (20), p. 1814-1817 (1984).

13. P. Pecheur, E. Kauffer, M. Gerl, Tight-binding study of the lattice vacancy in semiconductors // Proc. Intern. Conf. "Defects and Radiation Effects in Semiconductors”. Ser. № 46 (Nice, 1978). Inst. of Phys. Bristol and London, Chapter 2, p. 174179, 1979.

14. A.P. Dolgolenko, P.G. Litovchenko, M.D. Varentsov, G.P. Gaidar, A.P. Litovchenko, Particularities of the formation of radiation defects in silicon with low and high concentrations of oxygen // Phys. status solidi (b) 243 (8), p. 1842-1852 (2006).

15. P. Pellegrino, P. Leveque, J. Lalita, A. Hallen, C. Jagadish, B.G. Svensson, Annealing kinetics of vacancy-related defects in low-dose MeV self-ionimplanted n-type silicon // Phys. Rev. B 64, 195211-10 (2001).

16. R.E. Whan, Oxygen-defect complexes in neutronirradiated silicon // J. Appl. Phys. 37 (9), p. 33783382 (1966).

17. J.W. Corbett, G.D. Watkins, R.M. Chrenko, R.S. McDonald, Defects in irradiated silicon. II. Infrared absorption of the $\mathrm{Si}-\mathrm{A}$ center // Phys. Rev. 121 (4), p. 1015-1022 (1961).

18. B.G. Svensson, J.L. Lindstrom, Kinetic study of the 830 and $889 \mathrm{~cm}^{-1}$ infrared bands during annealing of irradiated silicon // Phys. Rev. B 34 (12), p. 8709-8717 (1986).

19. Kh. A. Abdullin, B.N. Mukashev, M.F. Tamendarov, and T.B. Tashenov, New defect states in irradiated p-type silicon // Phys. Lett. A 144 (3), p. 198-200 (1990).

20. A. Mattoni, F. Bernardini, and L. Colombo, Selfinterstitial trapping by carbon complexes in crystalline silicon // Phys. Rev. B 66 (19), 195214-6 (2002).

21. A.P. Dolgolenko, G.P. Gaidar, M.D. Varentsov, P.G. Litovchenko, The influence of germanium dopant on radiation hardness of silicon with high oxygen concentration // Problems of Atomic
Science and Technology. Series "Physics of Radiation Effects and Radiation Materials Science" 92, № 2, p. 28-36 (2008).

22. C.P. Ewels and R. Jones, S. Oberg, J. Miro and P. Deak, Shallow thermal donor defects in silicon // Phys. Rev. Lett. 77 (5), p. 865-868 (1996).

23. G.P. Gaidar, A.P. Dolgolenko, P.G. Litovchenko, Thermal annealing of radiation-induced defects in $\mathrm{n}-\mathrm{Si}$ irradiated with fast reactor neutrons // Ukr. J. Phys. 53 (7), p. 688-693 (2008).

24. L.I. Khirunenko, M.G. Sosnin, and Yu.V. Pomozov, L.I. Murin, V.P. Markevich and A.R. Peaker, L.M. Almeida, J. Coutinho, and V.J.B. Torres, Formation of interstitial carbon-interstitial oxygen complexes in silicon: Local vibrational mode spectroscopy and density functional theory // Phys. Rev. B 78 (15), 155203-8 (2008).

25. R. Jones and S. Öberg, Oxygen frustration and the interstitial carbon-oxygen complex in $\mathrm{Si} / /$ Phys. Rev. Lett. 68 (1), p. 86-89 (1992).

26. M.W. Thompson, Defects and Radiation Damage in Metals. Mir, Moscow, p. 25, 1971 (in Russian).

27. A.M. Frens, M.T. Bennebroek, A. Zakrzewski, J. Schmidt, W.M. Chen, E. Janzen, J.L. Lindstrom, B. Monemar, Observation of rapid direct charge transfer between deep defects in silicon // Phys. Rev. Lett. 72 (18), p. 2939-2942 (1994).

28. Y.H. Lee, N.N. Gerasimenko, J.W. Corbett, EPR study of neutron-irradiated silicon: A positive charge state of the $\langle 100\rangle$ split di-interstitial // Phys. Rev. B 14 (10), p. 4506-4520 (1976).

29. L.I. Murin, V.P. Markevich, J.L. Lindstrom, M. Kleverman, J. Hermansson, T. Hallberg, B.G. Svensson, Carbon-oxygen-related complexes in irradiated and heat-treated silicon: IR absorption studies // Solid State Phenomena 82-84, p. 57-62 (2002).

30. P.M. Mooney, L.J. Cheng, M. Suli, J.D. Gerson, and J.W. Corbett, Defect energy levels in borondoped silicon irradiated with $1-\mathrm{MeV}$ electrons // Phys. Rev. B 15 (8), p. 3836-3843 (1977).

31. C.P. Ewels and R. Jones, S. Öberg, J. Miro, P. Deak, Shallow thermal donor defects in silicon // Phys. Rev. Lett. 77 (5), p. 865-868 (1996).

32. A. Mattoni, F. Bernardini, and L. Colombo, Selfinterstitial trapping by carbon complexes in crystalline silicon // Phys. Rev. B 66, 195214-6 (2002). 